\title{
PREVALÊNCIA DOS HÁBITOS DE SUCÇÃO NÃO NUTRITIVA E SUA RELAÇÃO COM A IDADE, GÊNERO E TIPO DE ALEITAMENTO EM PRÉ-ESCOLARES DA CIDADE DE ARARAQUARA
}

\author{
Prevalence of nonnutritive sucking habits and their relationship \\ to age, gender and type of feeding in preschool children \\ from Araraquara-Brazil
}

\author{
Karina Eiras Dela Coleta Pizzol (1), Samuel da Silva Montanha (2), Edson Tenca Fazan ${ }^{(3)}$, \\ Eloisa Marcantonio Boeck ${ }^{(4)}$, Alessandra Nara de Souza Rastelli ${ }^{(5)}$
}

\begin{abstract}
RESUMO
Objetivo: avaliar a prevalência dos hábitos de sucção não nutritiva presentes em crianças pré-escolares do município de Araraquara-SP, buscando conhecer melhor suas características, distribuição e relação com o aleitamento materno. Método: aplicação de um questionário enviado aos pais ou responsáveis. A amostra foi composta por 1371 crianças com idades entre seis meses e cinco anos, na qual 702 crianças $(51,2 \%)$ apresentavam hábitos deletérios, num total de 812 hábitos relatados. Resultados: de acordo com os resultados, os hábitos foram mais prevalentes no gênero feminino $(55 \%)$ e na faixa etária entre seis meses e dois anos. O hábito mais comumente encontrado foi o de sucção chupeta (30\%), seguido pela sucção de mamadeira $(18,4 \%)$ e sucção digital $(7,6 \%)$, não havendo associação entre o tipo de hábito e condição sócio-econômica. Das crianças participantes, $1.239(90,4 \%)$ receberam aleitamento materno, sendo que o tempo de maior prevalência de amamentação foi entre seis meses e 12 meses (43\%), não necessariamente de forma exclusiva, mas por um período igual ou superior ao preconizado pela OMS. Conclusão: houve associação entre o tempo de amamentação com a presença e o tipo de hábito, visto que as crianças que receberam o aleitamento natural por um período superior a 12 meses tenderam a não desenvolver hábitos deletérios. Os resultados comprovam que quanto maior é o tempo de amamentação, menor é a prevalência de hábitos.
\end{abstract}

DESCRITORES: Aleitamento Materno; Hábitos; Prevalência

(1) Dentista, Professora dos Cursos de Graduação e Pós-graduação em Odontologia_ Departamento de Ortodontia do Centro Universitário de Araraquara (UNIARA).

(2) Aluno de Graduação do Curso de Odontologia do Centro Universitário de Araraquara (UNIARA).

(3) Aluno de Graduação do Curso de Odontologia do Centro Universitário de Araraquara (UNIARA).

(4) Dentista, Professora dos Cursos de Graduação e Pós-graduação em Odontologia_ Departamento de Ortodontia do Centro Universitário de Araraquara (UNIARA).

(5) Dentista, Professora dos Cursos de Graduação e Pósgraduação em Odontologia_ Departamento de Dentística Restauradora do Centro Universitário de Araraquara (UNIARA).

Conflito de interesses: inexistente

\section{INTRODUÇÃO}

Hábitos orais tem sido alvo de grande interesse dos profissionais de saúde devido a sua importância no desenvolvimento do sistema estomatognático. Durante anos, vários estudos e pesquisas ${ }^{1-9}$ têm sido realizados para isso. Os hábitos podem influenciar no crescimento facial, afetando as estruturas e as funções orofaciais e as relações oclusais, além de ter um papel determinante no desenvolvimento psicológico da criança.

Os hábitos são compreendidos como um automatismo adquirido, um comportamento que muitas 
vezes praticado torna-se inconsciente e passa a ser incorporado à personalidade. Eles podem ser divididos em nutritivos ou não nutritivos. O primeiro fornece nutrientes alimentares através da amamentação ou mamadeira. O segundo proporciona à criança um prazer especial, como a sensação de aquecimento e proteção, podendo tornar-se persistente quando adotado pela criança em resposta às frustrações e para satisfazer sua ânsia e necessidade de contato ${ }^{10}$.

A sucção é a primeira atividade muscular coordenada da criança e é diretamente ligada a deglutição e pode ser percebida antes do nascimento sob a forma de contrações bucais ou outras respostas reflexas através de ultrassom pélvico da mãe. É o exercício mais eficaz para o desenvolvimento dos órgãos da face e da fala.

O hábito de sucção é de grande importância para o recém-nascido, o qual depende da sucção oral instintiva para promover a sua satisfação nutricional. Nesse momento, durante a sucção, lábios, língua e mucosa oral experimentam uma sensação de prazer que constrói as primeiras funções psicológicas e relações interpessoais (mãe e filho). Nesta fase que pode se estender até os três anos de idade, a sucção faz parte do desenvolvimento normal da criança, atuando no fortalecimento da musculatura e no crescimento dentofacial. Entretanto, a persistência dos hábitos de sucção após essa fase, é considerada prejudicial ao desenvolvimento dos ossos da face e pode ser indicativa de problemas comportamentais ${ }^{8}$.

Tamanha é sua importância, que a Organização Mundial da Saúde (OMS) preconiza que o aleitamento natural seja realizado de forma exclusiva nos primeiros seis meses de vida. Por meio dele, a criança retira o alimento necessário para sua sobrevivência, além de trabalhar os principais grupos musculares do complexo maxilo-mandibular, criando tonicidade adequada para uma correta mastigação no futuro e coordenando funções essenciais como sucção, deglutição e respiração; o que minimizam as chances de que hábitos deletérios se instalem.

Assim, amamentação possui múltiplas funções servindo para alimentar a criança, exercitar a sua musculatura, suprir necessidades afetivas e neurológicas (de sucção). A falta ou ausência de amamentação natural irá aumentar a necessidade de uma sucção paralela. Quando ocorre o desmame precoce da criança, substituindo o aleitamento materno por mamadeiras, é minimizado o trabalho da musculatura perioral, visto que apenas $30 \%$ ou menos do potencial desses músculos é trabalhado. Com o êxtase emocional não atingido, a criança passa a buscar substitutos como o dedo e/ou a chupeta ${ }^{11}$.

Parte da responsabilidade do surgimento de hábitos orais viciosos ou deletérios decorre da necessidade de suprir carências afetivas ou neurais de sucção. Uma vez observados, o sistema estomatognático pode sofrer disfunções significantes em função da freqüência, intensidade e duração dos mesmos.

Há basicamente três teorias para explicar a etiologia e o prolongamento dos hábitos de sucção não nutritiva: satisfação insuficiente das necessidades de sucção infantil durante a amamentação, distúrbios emocionais (teoria psicanalítica), atribuídos a uma regressão e fixação na fase oral do desenvolvimento ${ }^{12,13}$.

Mas estes não são os únicos fatores desencadeantes de hábitos como dedo ou chupeta. O contexto social apresenta sua influência através de conflitos familiares, pressão escolar, emprego da mãe que colabora com a renda familiar de forma total ou parcial, além da dificuldade de acesso aos serviços odontológicos, algumas doenças respiratórias e problemas de fala, irritações associadas à erupção dental, interferências oclusais, entre outros ${ }^{5}$.

A exposição da criança a inúmeros fatores faz com que hábitos como a sucção de chupeta apresentem uma alta prevalência na população, por ser um bem de consumo de preço reduzido, amplamente acessível e que tradicionalmente faz parte do enxoval do bebê. Vários fatores sócio-econômico-culturais estão relacionados com o inicio de seu uso e sua utilização. Estudos revelam inúmeras desvantagens do seu uso, como a redução do período de amamentação natural, desenvolvimento de más oclusões entre outros ${ }^{14}$.

Quando se leva em conta a duração do hábito e a dificuldades que implicam na sua remoção, a sucção digital possivelmente seja o hábito que mereça maior atenção. A época do aparecimento da sucção digital tem alguma significância, pois aqueles que aparecem durante as primeiras semanas de vida são, geralmente, relacionados com os problemas alimentares. Algumas crianças começam a utilizar o hábito quando da erupção dos molares decíduos, mais tarde elas utilizam a sucção digital para a liberação de tensões emocionais, as quais não são capazes de vencer, consolando-se com um regresso a um padrão de comportamento infantil ${ }^{15}$.

Todos os hábitos de sucção devem ser estudados em virtude das suas implicações psicológicas, pois podem estar relacionados à fome, à satisfação do instinto de sucção, a insegurança ou mesmo a um desejo de atrair atenção, motivado pelo nascimento de um irmão ou pelo sentimento 
oriundo de alguma modificação no lar, como separação dos pais, conflitos familiares ou porque algum problema tenha absorvido o interesse dos pais ${ }^{13,16}$.

A família é a primeira e a mais importante unidade grupal na qual o indivíduo está inserido e é a partir dela que serão delineadas as características gerais do comportamento do indivíduo ${ }^{17}$. É ela que irá influenciar inconscientemente ou não, na instalação, desenvolvimento e remoção ou não, do hábito de sucção não nutritiva da criança.

Hábitos de sucção não nutritiva são frequentemente encontrados em crianças na fase da dentição decídua, aonde alteram o posicionamento dos dentes nos maxilares e suas estruturas de suporte. Diante da estreita relação entre hábitos e más oclusões, o presente estudo visa prover um levantamento da prevalência dos hábitos de sucção não nutritiva presentes em crianças pré-escolares do município de Araraquara-SP, buscando conhecer melhor suas características, distribuição e relação com o aleitamento materno, para que sejam montados programas de prevenção nos sistemas de ensino e saúde, auxiliando pais e educadores a removerem os hábitos deletérios de forma eficiente e na época adequada.

\section{MÉTODO}

O presente estudo refere-se a uma pesquisa transversal observacional com aplicação de questionário enviado aos pais de cada criança.

\section{Seleção da amostra}

Inicialmente, solicitou-se uma relação à Secretaria de Educação do Município de Araraquara, para obtenção do número total de crianças na faixa etária de seis meses a cinco anos, matriculadas em pré-escolas (municipais e particulares) na cidade de Araraquara, no ano letivo de 2010.

Com base no número total de alunos (10219), fez-se o cálculo da amostragem, utilizando a prevalência de hábitos de sucção não nutritiva descrita na literatura para esta faixa etária, com uma probabilidade de erro de $3 \%$ e com $95 \%$ de intervalo de confiança. Foi acrescido $10 \%$ a fim de se compensar eventuais perdas ou recusas em participar do estudo.

Para atingir o número de indivíduos da amostragem ( $\mathrm{n}$ ), as pré-escolas de Araraquara foram divididas por setores (Norte, Sul, Leste, Oeste) através de suas localizações no mapa da cidade, fornecido pela Secretaria de Educação do Município. Foram sorteadas três escolas municipais em cada setor tomando-se o cuidado para que as escolas não estivessem muito próximas uma das outras, evitando-se assim, que fatores socioeconômicos pudessem interferir nos resultados da pesquisa. Da mesma forma, foram sorteadas seis escolas particulares, de modo que o número de crianças nestas escolas representassem $20 \%$ do número total da amostra, reproduzindo a relação existente entre crianças matriculadas em escolas municipais $x$ escolas privadas.

O numero de escolas incluídas na pesquisa foi calculado de acordo com o numero mínimo necessário para que a pesquisa pudesse ter relevância estatística e representatividade na população estudada.

Cada escola sorteada recebeu um ofício da Secretaria de Educação, informando sobre a pesquisa e autorizando a realização da mesma na unidade selecionada.

Para minimizar eventuais erros do método, foi realizado um estudo piloto na qual, duas escolas (uma municipal e uma particular) foram selecionadas aleatoriamente da amostragem total, e os questionários utilizados na pesquisa, enviados aos pais de crianças matriculadas nas referidas escolas.

A amostragem foi composta atendendo aos seguintes critérios:

\section{CRITÉRIOS DE INCLUSÃO:}

- Crianças com idade entre seis meses a cinco anos, de ambos os gêneros, matriculadas em pré-escolas da rede municipal e particular de ensino de Araraquara, com a devida autorização dos responsáveis;

- Pais ou responsáveis por crianças entre seis meses a cinco anos, matriculadas em préescolas de Araraquara, que aceitem participar da pesquisa.

\section{CRITÉRIOS DE EXCLUSÃO:}

- Crianças que estejam acima ou abaixo da faixa etária estipulada pelos critérios de inclusão;

- Pais ou responsáveis que não tenham assinado o termo de consentimento livre e esclarecido ou que não tenham devolvido os questionários enviados.

\section{Aplicação do questionário}

A amostra foi composta por questionário estruturado, preenchido por pais ou responsáveis por crianças com idade entre seis meses a cinco anos, de ambos os gêneros, matriculadas em pré-escolas municipais e particulares de Araraquara (SP). O questionário apresentava cinco questões com informações sobre: idade, gênero, presença de aleitamento materno e duração, presença de hábitos deletérios, especificando o tipo do mesmo.

Para cada criança participante da pesquisa, foi enviado por meio do material escolar, um exemplar do questionário juntamente com um termo de 
consentimento livre e esclarecido direcionado aos pais, para uso das informações obtidas.

O presente trabalho foi submetido e aprovado pelo Comitê de ética da Faculdade de Odontologia de Araraquara - UNIARA sob número 1116/10.

Foram entregues um total de 4035 questionários nas 18 escolas participantes (12 municipais e seis particulares), obtendo-se um retorno de $1371(33,97 \%)$ questionários. Após o recolhimento dos mesmos, os dados foram tabulados no programa Excel 2007, realizada a análise descritiva e estatística utilizando-se o teste do Qui-quadrado para verificação de associação entre as variáveis ( $p<0,05)$; e posteriormente, os resultados organizados em Tabelas e Figuras para melhor interpretação dos mesmos.

\section{RESULTADOS}

Para melhor compreensão dos resultados, os mesmos serão apresentados na forma de Tabelas e Figuras a seguir.

Tabela 1 - Distribuição da amostra de acordo com a idade e o gênero

\begin{tabular}{lccccccc}
\hline \multirow{2}{*}{ Gênero } & \multicolumn{8}{c}{ Idade } & \multirow{2}{*}{ Total } \\
\cline { 2 - 7 } & $<\mathbf{1}$ ano & $\mathbf{1}$ ano & 2 anos & $\mathbf{3}$ anos & 4 anos & $\mathbf{5}$ anos & \\
\hline Feminino & 15 & 56 & 110 & 141 & 159 & 187 & 668 \\
Masculino & 16 & 63 & 102 & 139 & 157 & 226 & 703 \\
Total & 31 & 119 & 212 & 280 & 316 & 413 & 1371 \\
\hline
\end{tabular}

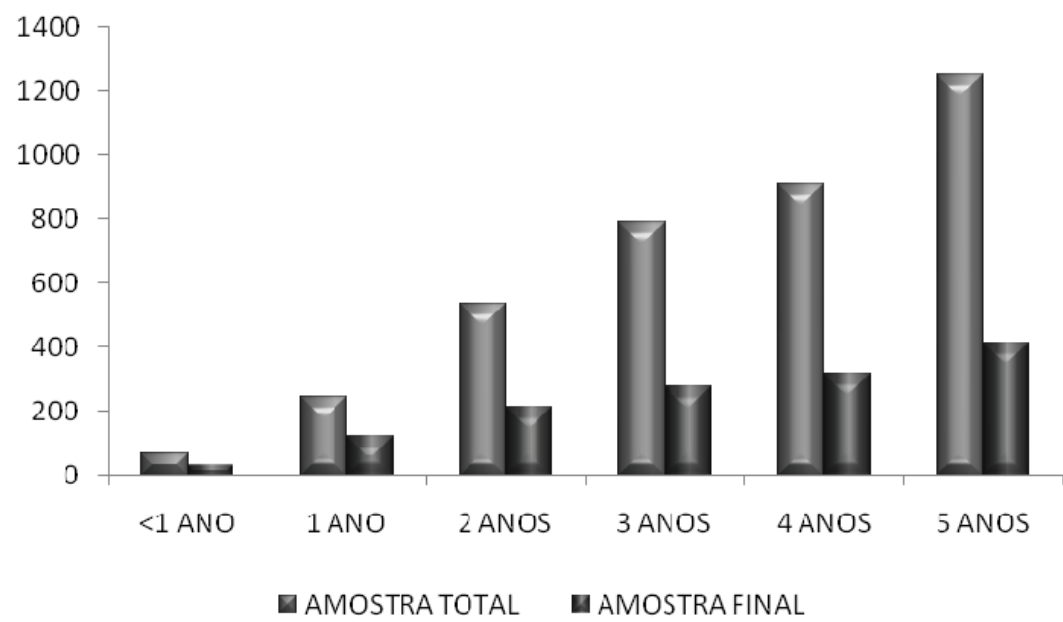

Figura 1 - Gráfico comparativo da distribuição da amostra final com a amostra total, de acordo com a idade

Tabela 2 - Tempo de amamentação de acordo com o gênero e o tipo de escola

\begin{tabular}{|c|c|c|c|c|c|}
\hline \multirow{3}{*}{ Variável } & \multicolumn{4}{|c|}{ Amamentação } & \multirow{3}{*}{ Total } \\
\hline & \multirow{2}{*}{ Ausente } & \multicolumn{3}{|c|}{$\begin{array}{r}\text { Presente } \\
\end{array}$} & \\
\hline & & Até 5 meses & 6-12 meses & $>12$ meses & \\
\hline \multicolumn{6}{|l|}{ Gênero } \\
\hline Feminino & 65 & 147 & 271 & 185 & 668 \\
\hline Masculino & 69 & 148 & 260 & 226 & 703 \\
\hline \multicolumn{6}{|l|}{ Escola } \\
\hline Municipal & 111 & 244 & 434 & 370 & 1159 \\
\hline Particular & 23 & 51 & 97 & 41 & 212 \\
\hline Total & 134 & 295 & 531 & 411 & 1371 \\
\hline
\end{tabular}


Tabela 3 - Tipo de hábito deletério de acordo com gênero, tipo de escola, amamentação e idade

\begin{tabular}{|c|c|c|c|c|c|c|c|c|c|}
\hline \multirow{4}{*}{ Variável } & \multicolumn{8}{|c|}{ Tipos de hábitos } & \multirow{4}{*}{ Total } \\
\hline & \multirow{3}{*}{ Ausente } & \multicolumn{7}{|c|}{ Presente } & \\
\hline & & \multicolumn{2}{|c|}{ Chupeta } & \multicolumn{2}{|c|}{ Dedo } & \multicolumn{2}{|c|}{ Mamadeira } & \multirow{2}{*}{ Outros } & \\
\hline & & Isolada & Associada & Isolada & Associada & Isolada & Associada & & \\
\hline \multicolumn{10}{|l|}{ Gênero } \\
\hline Feminino & 300 & 173 & 53 & 50 & 11 & 68 & 50 & 23 & 428 \\
\hline Masculino & 369 & 140 & 44 & 36 & 7 & 90 & 44 & 23 & 384 \\
\hline \multicolumn{10}{|l|}{ Escola } \\
\hline Municipal & 555 & 268 & 83 & 74 & 18 & 134 & 80 & 43 & 700 \\
\hline Particular & 114 & 45 & 14 & 12 & 0 & 24 & 14 & 3 & 112 \\
\hline \multicolumn{10}{|c|}{ Amamentação } \\
\hline Ausente & 37 & 49 & 14 & 9 & 1 & 15 & 13 & 8 & 109 \\
\hline Até 5 meses & 100 & 104 & 34 & 17 & 8 & 30 & 34 & 11 & 238 \\
\hline 6-12 meses & 248 & 123 & 37 & 49 & 4 & 60 & 36 & 14 & 323 \\
\hline$>12$ meses & 282 & 38 & 12 & 11 & 5 & 53 & 11 & 14 & 144 \\
\hline \multicolumn{10}{|l|}{ Idade } \\
\hline$<1$ ano & 10 & 12 & 5 & 1 & 3 & 3 & 3 & 0 & 27 \\
\hline 1 ano & 49 & 55 & 28 & 3 & 1 & 6 & 4 & 2 & 99 \\
\hline 2 anos & 77 & 69 & 23 & 13 & 2 & 20 & 26 & 6 & 159 \\
\hline 3 anos & 122 & 68 & 22 & 17 & 1 & 40 & 24 & 9 & 181 \\
\hline 4 anos & 68 & 47 & 14 & 28 & 7 & 39 & 23 & 10 & 168 \\
\hline 5 anos & 243 & 62 & 5 & 24 & 4 & 50 & 14 & 19 & 178 \\
\hline
\end{tabular}

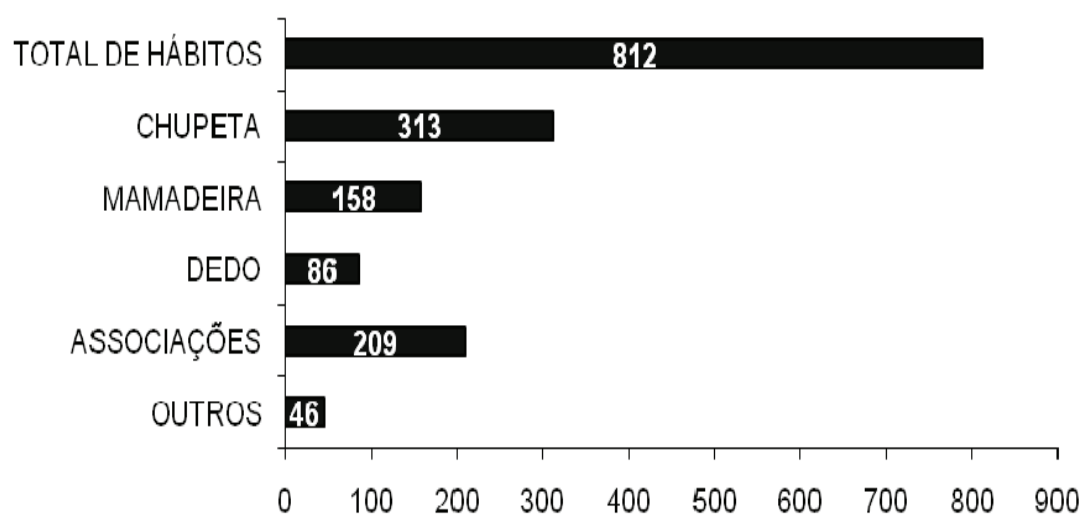

Outros: Onicofagia, bruxismo, chupar pano, chupar lábio, chupar objetos, chupar língua e onicofagia + bruxismo.

Figura 2 - Distribuição dos tipos de hábitos

\section{DISCUSSÃO}

A amamentação é um ato de amor, além de ser um verdadeiro exercício para o bebê, pois favorece a sua saúde mental e psíquica; e seu correto crescimento craniofacial. Crianças que não recebem amamentação natural de forma adequada, não conseguem suprir a fome neural de sucção; e por isso, muitas adquirem hábitos de sucção não nutritiva como dedo ou chupeta ${ }^{11}$.

A amamentação natural durante os seis primeiros meses de vida tem papel fundamental não apenas no aspecto nutricional, mas também para o fortalecimento imunológico e para o correto desenvolvimento da oclusão ${ }^{18}$. É por meio da amamentação natural que são alcançados estímulos neurais essenciais para um correto desenvolvimento muscular e ósseo e que são prevenidas boa parte das más oclusões em idade precoce.

Estudos $^{2,17,19,20}$ mostram que quando a mãe é orientada sobre a importância do aleitamento natural, ocorre um prolongamento do período de aleitamento materno exclusivo e um atraso na época de oferta da chupeta. Por isso, uma correta 
orientação dos pais logo após o nascimento da criança, no próprio ambiente hospitalar, é de grande importância para a prevenção do desmame precoce e introdução de outros meios de sucção como a mamadeira e a chupeta.

Em nossa pesquisa, os resultados (tabela 2) mostraram que a grande maioria das mães amamentou seus filhos $(90,4 \%)$, confirmando que em nosso município as mães recebem orientação adequada sobre a importância do aleitamento materno, embora nem todas tenham realizado a amamentação natural exclusiva. A introdução do aleitamento artificial contribui para que a criança futuramente introduza chupetas, ou até mesmo objetos como forma de suprir um desmame precoce

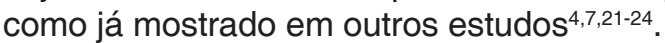

Embora a amamentação seja comum, raramente é exclusiva, e tem uma duração relativamente curta. Usar chupeta, tomar chá no primeiro dia em casa, ter mãe com escolaridade até o primeiro ou segundo grau ou primípara, representam maior risco de não ter amamentação exclusiva até 120 dias de vida. $\mathrm{O}$ aleitamento materno exclusivo nos primeiros três meses de vida é pouco praticado, em especial quando a mãe trabalha fora do lar, o pai tem pouca escolaridade e a criança faz uso de chupeta, o que reforça a necessidade de se continuar estimulando a amamentação exclusiva nos primeiros meses de vida $^{25}$

Com relação ao tempo de aleitamento materno, verificou-se que $68,7 \%$ das crianças foram amamentadas por um período mínimo de seis meses (tabela 2). Esses resultados são extremamente favoráveis e vão de encontro com o que preconiza a OMS que orientam que as mães amamentem seus filhos de forma exclusiva durante os seis primeiros meses de vida, para um correto desenvolvimento psicológico e fisiológico. Nossos valores foram superiores aos encontrados por Serra-Negra et al. ${ }^{26}$ (1997), Oliveira et al. ${ }^{27}$ (2006), Furtado \& Vedovelo-Filho ${ }^{21}$ (2007), e, que verificaram valores entre $51,4 \%$ e $55,8 \%$ de aleitamento materno em um período mínimo de seis meses. Quando considerado períodos de aleitamento materno superiores há 12 meses, nosso estudo também mostrou um índice elevado (30\%), com o aleitamento materno estendendo-se em alguns casos, até 60 meses. A amamentação natural por um longo período foi encontrada com maior frequência entre crianças que frequentam escolas da rede pública de ensino. Uma possível explicação para o fato seja que devido à condição sócio-cultural, algumas mães tenham um número maior de filhos e em intervalos menores, fazendo com que a oferta do aleitamento materno aos filhos mais novos também se estenda para os filhos mais velhos. Embora esta característica tenha sido observada, não houve associação estatisticamente significante entre presença ou ausência de amamentação natural e condição sócio-econômica.

A maioria das crianças que participaram da nossa pesquisa estava na faixa etária entre três e cinco anos, havendo uma distribuição uniforme entre os gêneros (tabela 1). De forma geral, não foi observada diferença no tempo de amamentação natural entre os gêneros (tabela 2). Apenas nas crianças que foram amamentadas até os cinco meses, houve um maior percentual para o gênero feminino, quando comparado aos outros grupos, embora esta diferença não fosse estatisticamente significante. Quando comparado o número total de crianças matriculadas nas escolas participantes (amostra total), com o número de crianças que retornaram o questionário (amostra final), evidenciou-se um percentual maior na participação de crianças na faixa etária entre seis meses a um ano (Figura 1).

Com relação à condição sócio-econômica (Tabela 2), representada pelo tipo de escola (privada ou municipal), observou-se que o percentual de mães que não amamentou de forma natural seus filhos, foi maior na rede privada $(10,8 \%)$, quando comparada à rede municipal $(9,5 \%)$. Esta mesma relação, também foi observada para tempo de amamentação de até cinco meses (privada 24\%, municipal 21\%). Entretanto, esta diferença foi maior entre os dois grupos, para períodos de amamentação natural superior à 12 meses, na qual 31,9\% das crianças estavam em escolas municipais e $19,9 \%$ em escolas privadas, havendo uma associação estatisticamente significante $(p=0.0012)$ entre tempo de amamentação e tipo de escola. Isso mostra que em nosso estudo, as mães com condição sócio-econômica inferior, representada pelas escolas municipais, tendem a amamentar mais seus filhos de forma natural, e por um período maior. Estudos como o de Tomita et al. ${ }^{16}$ (2000) e Carrascoza et al. ${ }^{19}$ (2005) mostram que a condição sócio-econômica está relacionada com o tempo de amamentação, pois em famílias de baixa renda o tempo de amamentação tende a ser maior do que em famílias com uma renda maior.

Quando a amamentação natural não é realizada com livre demanda e por tempo suficiente, dá espaço à instalação de hábitos de sucção não nutritiva que são os grandes causadores de alteração oclusais e estão diretamente associados ao comportamento da criança como um todo. Dentro desse contexto, o conhecimento da prevalência e dos fatores associados à sua instalação e persistência, adquire uma importância fundamental ${ }^{28}$.

Dentre os fatores que contribuem para o desmame cada vez mais precoce, estão a complexidade dos estilos de vida modernos e suas 
implicações, como a divisão do trabalho pelo casal, retorno ao emprego por parte da mãe, renda familiar baixa, ser primípara, ser adolescente, não receber orientação no pré-natal, tipo de parto, a pandemia da AIDS, as afecções da mama (mastite, fissura, ingurgitamento mamário, abscessos e outras), problemas com o neonato (fenilcetonúria, galactosemia), os mitos arraigados culturalmente por gerações (pouco leite, leite fraco e as implicações estéticas-flacidez e queda das mamas) e as influências externas familiares, de amigos e de vizinhos ${ }^{17,25,29}$.

A utilização de chupetas e mamadeiras é o fator determinante que pode comprometer o sucesso do aleitamento materno. Mesmo que as mães expressem desejo de amamentar seu filho, se elas acreditarem que tais utensílios sejam necessários, o processo de amamentação poderá ser frustrante. Barreira \& Machado $^{17}$ (2004) citam que não se pode culpar a falta de informação das pessoas, no que diz respeito à influência negativa dos bicos artificiais, já que algumas, em seu estudo, demonstraram saber que não é aconselhado o seu uso, mas lançam mão desses artifícios para diminuir a freqüência dos episódios de choro da criança, e consequentemente melhorarem seu próprio bem estar.

A literatura mostra uma grande variabilidade nos índices de crianças portadoras de hábito de sucção não nutritiva, com valores entre $27 \%$ a $92 \%^{8-11,30,31}$. A alta prevalência de hábitos na população infantil, segundo a literatura 4,7,11,14,17,21-23,29,32,33 está intimamente ligada à duração da amamentação natural.

Em nossa amostragem, os hábitos deletérios estavam presentes em $51,2 \%$ das crianças, sendo mais prevalente no gênero feminino (55\%) e na faixa etária de seis meses a dois anos (Tabela 3). Nesta faixa etária, as crianças mostram-se mais inquietas e os pais na tentativa de acalmá-las, ofertam a chupeta com frequência. Como essa idade também sugere a época de desmame, é comum que a necessidade de sucção seja substituída pelo dedo ou pela chupeta. Esta última é um bem de consumo de preço reduzido, amplamente acessível à população e que tradicionalmente faz parte do enxoval do bebê. Sua utilização é estimulada pelos pais, frente ao choro infantil, desde as idades mais tenras. A chupeta é também descrita na literatura com os termos "pacifer" ou "comforter". Parece decorrer daí a conotação de que sua utilização deva ser indicada com os objetivos de "pacificar" ou "confortar" a criança inquieta ${ }^{16}$.

O hábito mais comumente encontrado na amostra (Figura 2) foi o de sucção de chupeta (30\%) e isso corrobora com vários outros estudos ${ }^{7,26-28} \mathrm{e}$ diverge de outros onde a mamadeira é o hábito mais presente $^{2,31,34}$. Embora a maioria dos responsáveis pelas crianças considere que a recomendação do uso da chupeta deva ser cautelosa em função de eventuais problemas de saúde que possa ocasionar em bebês, boa parte das mães oferece a chupeta para o filho com objetivo de acalmá-lo, na convicção de que não ofertá-la é sinônimo de falta de cuidado e amor com o seu bebê ${ }^{35}$.

Outro dado encontrado em nossa pesquisa é que quando relacionado o tipo de hábito com o gênero (Tabela 3), notou-se que a mamadeira é o hábito mais prevalente no gênero masculino, e a sucção digital e da chupeta foram mais encontrados no gênero feminino, devido a fatores emocionais que influenciam a instalação de um hábito deletério. Embora essas características tenham sido observadas, não houve associação estatisticamente significante para gênero e tipo de hábito $(p=0.0514)$ bem como para a presença de hábito e o gênero $(p=0.7250)$.

Sempre que um hábito deletério se instalar ou perdurar na criança após os três a quatro anos de idade, deve merecer atenção especial do ponto de vista ortodôntico. Segundo o que a literatura ${ }^{1,5,34}$ descreve, os efeitos dos hábitos, existentes antes dessa idade, sofrem um processo de correção espontânea na maioria dos casos, ou seja, ainda que a manifestação da má oclusão seja proveniente de hábitos em período anterior a idade de três anos, a interrupção dos hábitos bucais a partir dessa idade tem apresentado um prognostico favorável. Caso o hábito se estenda por uma idade superior a quatro anos, ou após o início da irrupção dos dentes permanentes, há uma forte tendência de que a má oclusão provocada pelo hábito, necessite de tratamento ortodôntico para sua correção.

Nossa amostra evidenciou que 702 crianças apresentavam hábitos deletérios, embora o número de hábitos presentes tenha sido superior (total de 812). Isso mostra que muitas crianças apresentavam mais de um hábito simultaneamente, como por exemplo, sucção de dedo e chupeta ou sucção de chupeta e mamadeira. Um total de 209 crianças $(25,7 \%)$ apresentou algum tipo de associação. Outros hábitos descritos pelos pais, além da chupeta, dedo e mamadeira (os mais frequentes) foram: bruxismo $(1,7 \%)$, onicofagia $(1,8 \%)$, e sucção de lábio $(0,3 \%)$, além de chupar pano, chupar objetos, chupar a língua e chupar o lábio inferior, descritos na Tabela 3 e Figura 2 como outros. De acordo com a análise estatística (teste qui-quadrado) não foi encontrado associação entre tipo de hábito e condição sócio-econômica (tipo de escola).

Embora os resultados não tenham evidenciado uma associação estatisticamente significante $(p=0.1122)$ para presença ou ausência de amamentação e tipo de hábito, contudo esta 
associação mostrou-se estatisticamente significante $(p<0.0001)$ para associação entre tempo de amamentação e tipo de hábito. De acordo com os resultados, quanto maior o tempo de amamentação, menor a prevalência de hábitos. Isso pode ser evidenciado pelos valores obtidos das crianças que receberam o aleitamento natural por um período superior a 12 meses, na qual apresentaram um índice de hábitos deletérios de aproximadamente $31 \%$, contra um índice de $61 \%$ de hábitos, das que não foram amamentadas. Estes dados são condizentes com o trabalho de Serra-Negra et al. $(1997)^{26}$ que constataram que em seus estudos que crianças que nunca receberam aleitamento materno ou por um período de até um mês, apresentaram um risco de desenvolver hábitos deletérios sete vezes superior $(O . R .=7,1)$ com relação àquelas que foram amamentadas por um período de no mínimo seis meses. Almeida et al. ${ }^{2}(2007)$ e Leite-Cavalcanti et al. ${ }^{7}(2007)$ também mostraram em suas pesquisas que quando se analisa o tempo de aleitamento e a presença de hábito, observa-se que quanto menor o tempo de aleitamento natural maior a prevalência de hábitos bucais. Isto porque a livre demanda do aleitamento materno faz com que a criança consiga não apenas saciar a fome fisiológica, mas também a fome neural, não havendo necessidade de sucção complementar. Esta relação também foi observada por Telles et al. ${ }^{36}$ (2009) que encontraram que a duração da amamentação tem um efeito inversamente proporcional ao uso da chupeta.

A remoção de hábitos de sucção não nutritiva sempre irá necessitar de uma abordagem multidisciplinar, buscando obter um controle tanto para aspectos físicos como psicológicos da criança. A orientação aos pais é de suma importância, já que o desmame precoce e a oferta de chupeta e mamadeira é de iniciativa dos mesmos, muitas vezes sem saber dos malefícios que podem estar causando para seu filho futuramente. Programas na rede pública de saúde, na qual os pais fossem orientados desde o pré-natal pelo médico, e encaminhados a um dentista nos primeiros meses de vida da criança, é de caráter fundamental na prevenção do desmame precoce e da introdução e manutenção de hábitos deletérios, capazes de atuar de forma prejudicial no desenvolvimento muscular e esquelético facial da criança.

\section{CONCLUSÃO}

1. Os hábitos deletérios são bastante comuns em crianças em idade pré-escolar, principalmente no gênero feminino e na faixa etária de seis meses a dois anos;

2. A sucção de chupeta foi o hábito mais comumente encontrado;

3. A grande maioria das crianças participantes do estudo recebeu aleitamento materno, sendo que o tempo de maior prevalência de amamentação foi entre seis meses a 12 meses. Em nosso estudo, as mães com condição sócioeconômica inferior, representada pelas escolas municipais, tenderam a amamentar mais seus filhos de forma natural, e por um período maior;

4. De acordo com os resultados, as crianças que receberam o aleitamento natural por um período superior a 12 meses tenderam a não desenvolver hábitos deletérios, comprovando que a amamentação natural é um dos métodos mais eficazes na prevenção de hábitos de sucção não nutritiva. 


\section{ABSTRACT}

Purpose: to evaluate the prevalence of nonnutritive sucking habits in preschool children from Araraquara-SP, seeking to better understand their characteristics, distribution and relation to breastfeeding. Method: application of a questionnaire sent to parents or guardians. The sample comprised 1371 children aged between 6 months and 5-year old, where 702 children $(51.2 \%)$ had deleterious habits, from a total of 812 reported habits. Results: the habits were more prevalent in women (55\%) and aged between 6 months and 2 years. The most commonly found practice was sucking a pacifier $(30 \%)$, followed by suction bottle $(18.4 \%)$ and sucking $(7.6 \%)$, there was no association between the type of habit and socioeconomic status. From the participating children, $1,239(90.4 \%)$ were breastfed, and the length of breastfeeding was most prevalent between 6 months and 12 months (43\%), not necessarily exclusive but for a period not less than the recommended by WHO. Conclusion: there was an association between duration of breastfeeding in the presence and type of habit, since children who received breastfeeding for a period exceeding 12 months tended not to develop harmful habits. The results show that the greater the duration of breastfeeding is, the lower becomes the prevalence of habits.

KEYWORDS: Breastfeeding; Habits; Prevalence

\section{REFERÊNCIAS}

1. Aguiar KF, Patussi EG, Areal R, Bosco VL. Remoção de hábitos de sucção não-nutritiva: integração da odontopediatria, psicologia e família. Arquivos em Odontologia. 2005; 41(4): 273-368.

2. Almeida MEC, Melo NS, Maia SA, Costa AMM, Souza KR. A influência do desmame precoce no desenvolvimento de hábitos bucais deletérios. ConScientiae Saúde. 2007; 6(2): 227-34.

3. Bishara SE, Warren JJ, Broffitt B, Levy SM. Changes in the prevalence of nonnutritive sucking patterns in the first 8 years of life. Am $\mathrm{J}$ Orthod Dentofacial Orthop. 2006; 130 (1): 31-6.

4. Bittencourt LP, Bastos EPS, Modesto A, Tura LFR. Hábitos de sucção: desigualdades sociais na área de saúde. Pesq Bras Odontoped Clin Integr. 2002; 2 (2/3): 63-8.

5. Cavassani VGS, Ribeiro SG, Nemr NK, Greco AM, Kohle J, Lehn CN. Hábitos orais de sucção: estudo piloto em população de baixa renda. Rev. Bras. Otorrinolaringol. 2003; 69 (1): 106-10.

6. Cotrim LC, Venancio SI, Escuder MML. Uso de chupeta e amamentação em crianças menores de quatro meses no estado de SãoPaulo. Rev. Bras. Saúde Matern. Infant. 2002; 2 (3): 245-52.

7. Leite-Cavalcanti A, Medeiros-Bezerra PK, Moura C. Aleitamento natural, aleitamento artificial, hábitos de sucção e maloclusões em pré-escolares brasileiros. Rev. Salud Publica. 2007; 9 (2): 194-204.

8. Santos SA, Holanda AL, Sena MF, Gondim LA, Ferreira MA. Nonnutritive sucking habits among preschool aged children. J Pediatr. 2009; 85 (5): 408-14.

9.Valença AMG, Vasconcelos FGG, Cavalcanti AL, Duarte RC. Pesq Bras Odontoped Clin Integr. 2001; 1 (1): 17- 23.

10.Tartaglia SMA, Souza RG, Santos SRB, SerraNegra JMC, Pordeus IA. Hábitos orais deletérios: avaliação do conhecimento e comportamento das crianças e suas famílias. J Bras Odontopediatr Odontol Bebê. 2001; 4 (19): 203-9.

11. Heringer MRC, Reis M, Pereira LFS, Di Ninno CQMS. A influência da amamentação natural no desenvolvimento dos hábitos orais. Rev CEFAC. 2005; 7 (3): 307- 10.

12.Ribeiro LDS, Mello SMMS, Santana VML. O que os pais sabem sobre a chupeta de seus filhos? Uma análise qualitativa da questão, vista sob a ótica odontopediátrica. J Bras Ortodon Ortop Facial. 1999; 4 (22): 327-36.

13.Serra- Negra JMC, Vilela LC, Rosa AR, Andrade ELSP, Paiva SM, Pordeus IA. Hábitos bucais deletérios: os filhos imitam as mães na adoção destes hábitos? Revista Odonto Ciência. 2006; 21 (52): 146-52.

14.Pinto MCGL, Melo GFB, Colares V, Katz CRT. Fatores sócio-econômico-culturais relacionados ao uso da chupeta em crianças de zero a quatro anos da cidade do Recife-PE. Arq em Odontol. 2003; 39(4): 285- 96.

15.Tanaka O, Kreia TB, Bezerra JGB, Mauro H. A maloclusão e o hábito de sucção de diferentes dados. Jornal Brasileiro de Ortodontia \& Ortopedia Facial. 2004; 9 (0): 276- 83. 
16.Tomita NE, Bijella VT, Franco LJ. Relação entre hábitos bucais e má oclusão em pré-escolares. Rev Saúde Pública. 2000; 34 (3): 299-303.

17.Barreira SMC, Machado MFAS. Amamentação: compreendendo a influência do familiar. Acta Scientiarum. Health Sciences. 2004; 26 (1): 11-20. 18. Neiva FCB, Cattoni DM, Ramos JLA, Issler $\mathrm{H}$. Desmame precoce: implicações para o desenvolvimento motor-oral. Jornal de Pediatria. 2003; 79 (1): 7-12.

19.Carrascoza KC, Costa-Júnior AL, Ambrozano GMB, Moraes ABA. Análise de variáveis biopsicossociais relacionadas ao desmame precoce. Paidéia. 2005; 15 (30): 93-104.

20.Faleiros FTV, Trezza EMC, Carandina L. Aleitamento materno: fatores de influência na sua decisão e duração. Rev. Nutr. Campinas. 2006; 19 (5): 623-30.

21.Furtado ANM, Vedovello-Filho M. A influência do período de aleitamento materno na instalação dos hábitos de sucção não nutritivos e na ocorrência de maloclusão na dentição decídua. RGO. 2007; 55 (4): 335-41.

22.Souza DFRK, Valle MAS, Pacheco MCT. Relação clínica entre hábitos de sucção, má oclusão, aleitamento e grau de informação prévia das mães. Revista Dental Press Ortodon Ortop Facial. 2006; 11 (6): 81-90.

23.Gimenez CMM, Moraes ABA, Bertoz AP, Bertoz FA, Ambrosano GM. Prevalência de más oclusões na primeira infância e sua relação com as formas de aleitamento e hábitos. $\mathrm{R}$ Dental press Ortodont Ortop Facial. 2008; 13 (2): 70- 83.

24.Peres KG, De Oliveira Latorre Mdo R, Sheiham A, Peres MA, Victora CG, Barros FC. Social and biological early life influences on the prevalence of open bite in Brazilian 6- year- olds. Int $\mathrm{J}$ Pediatr Dent. 2007; 17 (1): $41-9$.

25.Mascarenhas MLW, Albernaz EP, Silva MB, Silveira RB. Prevalence of exclusive breastfeeding and its determiners in first 3 months of life in South of Brasil. J Pediatr. 2006; 82(4): 289- 94.

http://dx.doi.org/10.1590/S1516-18462012005000001

RECEBIDO EM: 31/03/2011

ACEITO EM: 27/06/2011

Endereço para correspondência:

Karina Eiras Dela Coleta Pizzol

Av. Cristovão Colombo, 614

Araraquara - SP

CEP: $14801-200$

E-mail: nkpizzol@ig.com.br
26.Serra-Negra JMC, Pordeus IA, Rocha-Jr JF. Estudo da associação entre aleitamento, hábitos bucais e maloclusões. Rev Odontol Univ São Paulo. 1997; 11 (2): 79-86.

27. Oliveira AB, Souza FP, Chiappetta ALML. Relação entre hábitos de sucção não-nutritiva, tipo de aleitamento e má oclusões em crianças com dentição decídua. Rev CEFAC. 2006; 8 (3): 352-9.

28.Santos SA. Hábitos de sucção não nutritiva em crianças pré-escolares. [dissertação]. Natal: Universidade Federal do Rio Grande do Norte; 2005.

29.Maia MGM, Tavares-Neto J, Rego RCF, Muniz PT. Fatores associados à interrupção do aleitamento materno nas crianças menores de seis meses de idade, da cidade do Rio Branco (Acre). Rev Baiana Saúde Pública. 2006; 30(1): 129-40.

30. Hebling SR, Cortellazzi KL, Tagliaferro EP, Hebling E, Ambrosano GM, Meneghim Mde C, Pereira AC. Relashionship between maloclusion and behavioral, demografic and socioeconomic variables: a cross- seccional study of 5 - year- olds. J Clin Pediatr Dent. 2008; 33 (1): 75-9.

31.Crato NA, Oliveira DV, Cunha TO, Motta AR. Hábitos orais deletérios e relação com aspectos comportamentais e psicológicos de crianças de creches públicas de Belo Horizonte. In: Anais do Sétimo Encontro de Extensão da Universidade Federal de Minas Gerais. 2004 set 12-15; Belo Horizonte(MG).

32.França GVA, Brunken GS, Silva SM, Escuder MM, Venâncio SI. Determinantes da amamentação no primeiro ano de vida em Cuiabá, Mato Grosso. Rev. Saúde Pública J. Public Health. 2007; 41(5): 711- 8.

33. Bittencourt LP, Modesto A, Bastos EPS. Influência do aleitamento sobre a freqüência dos hábitos de sucção. Rev Bras Odontol. 2001; 58(3): 191- 3.

34.Galvão ACUR, Menezes SFL, Nemrk. Correlação de hábitos deletérios entre crianças de 4:00 a 6:00 anos de escola pública e escola particular da cidade de Manaus -AM. Rev CEFAC. 2006; 8 (3): 328-36. 35.Fófano CZN, Mialhe FL, SILVA RP, Brum SC. Conhecimentos, atitudes e práticas maternas em relação ao uso da chupeta. Pesq Bras Odontoped Clin Integr. 2009; 9 (1):119-23.

36. Telles FB, Ferreira RI, Magalhães I do N, Scavone-Junior $\mathrm{H}$. Effect of breast-and-bottlefeeding duration on the age of pacifier use persistence. Bras Oral Res. 2009; 23(4):432-8. 